\title{
AN IMPRESSION OF THE WORK OF THE SECTION OF TUBERCULOSIS AT THE GLASGOW MEETING OF THE BRITISH MEDICAL ASSOCIATION.
}

\author{
By A. S. M. MACGREGOR, \\ O.B.E., M.D., D.P.H.,
}

Joint Secretary of the Tuberculosis Section of the British Medical Association, Glasgow Meeting, I922; Assistant Medical Officer, Public Health Department of the City of Glasgow.

THE Section of Tuberculosis in connection with the British Medical Association's Ninetieth Annual Meeting at Glasgow met on Thursday, July 26, under the Presidency of Professor Sir Robert Philip, M.D., LL.D., P.R.C.P. (Edin.). This was the first time that a Tuberculosis Section had been held in connection with the Annual Meeting of the Association, and the President, in his opening address, referred to this fact, and traced the progress which had been made in dealing with tuberculous disease since the last meeting of the Association in I 888. He traced the decline in the incidence of the disease, which had been greater in Scotland than in England, since that date, and described the lines on which anti-tuberculosis measures had developed.

The feature of the meeting was the opening paper by Dr. E. Rist (of Paris) on "The Clinical Differentiation of Pulmonary Tuberculosis from Other Respiratory Affections." Dr. Rist's paper was a most interesting one, and amounted to a plea for greater accuracy in differential diagnosis, and the necessity for careful investigation of doubtful cases. It was the lecturer's opinion that there was still a tendency to overdiagnosis of pulmonary tuberculosis. Dr. Rist gave figures from his own experience and that of others showing that the proportion of errors in the routine diagnosis of the disease is apt to be very large, and he reminded his hearers how the experiences of the War convinced the majority that there was something wrong in our every-day methods of discriminating tuberculosis from other respiratory diseases. Summarizing his remarks under four heads, Dr. Rist dealt with: I. The Skin Reaction, which merely detected the initial steps of infection, and was not a diagnostic sign of tuberculous disease. 2. X Rays as an Aid to Diagnosis.-Great stress was laid upon the value of radiological examinations as an aid to accurate diagnosis, and it was shown that, in fact, many cases cannot be accurately diagnosed without reference to X-ray findings. 3. Examination of Sputum.-Modern methods of detecting bacilli in the sputum have been improved. A complete examination of a supposed tuberculous patient implies repeated and conscientious 


\section{I86 THE BRITISH JOURNAL OF TUBERCULOSIS}

sputum examination. 4. Infections of the Upper Respiratory Passages.Infections, catarrhs; and mechanical obstruetions of the upper respiratory passages give rise to symptoms liable to be mistaken for tuberculosis; they may influence the bronchial tree and even the tissue of the lung. Dr. Rist then dealt with the diseases mistaken for pulmonary tuberculosis, in regard to which reference should be made to the paper itself for details. His main attitude towards diagnosis may be summed up as follows in his own words: "The first step after analyzing the symptoms is to look for positive signs of a localized lung lesion. And here begins properly the task of the physician. Percussion, auscultation, and the other methods of physical examination, must be applied without any bias. I mean that the physician should not, at this step, ask himself the question: Has this patient tuberculosis? but simply : Is there, either in the lung or elsewhere, a localized lesion which may account for the symptoms observed? I need not emphasize again the value of an X-ray examination of the chest to show whether such a lesion can be demonstrated or not. If it cannot be demonstrated in the lung, then let us look for it in some other part of the body. And here, after due consideration of the cardio-vascular and other systems, comes in the careful examination of the upper air passages by an expert. It will often, I dare say, prove fruitful of a correct diagnosis." As regards the finding of tubercle bacilli in the expectoration, Dr. Rist emphasized the necessity for repeated examinations, and stated that, in his opinion, one positive result may mean very little. The following took part in the discussion: Professor S. Lyle Cummins, Dr. Marcus Paterson, Dr. James Crocket, Dr. A. Hope Gosse, Dr. Fergus Hewat, Dr. Ian Struthers Stewart, Dr. Muthu, Dr. Prest, and Dr. Gillies of Australia. All the speakers indicated their high appreciation of Dr. Rist's paper, and Dr. Gosse took the opportunity of making an important communication of an investigation carried out by himself and Dr. Lisle Punch on complement fixation as a test for activity in a tuberculous lesion. The results quoted by the speaker were very striking, and are in course of publication.

A paper on "Some Aspects of the Treatment of Non-pulmonary Tuberculosis" was read by Dr. James Taylor, Visiting Surgeon to the Tuberculosis Hospital of Glasgow Corporation at Robroyston, where there is accommodation for about 300 patients of this type. The general treatment is based on that of Dr. Rollier, as practised at Leysin, with modifications appropriate to differences in climate. The speaker considered that rapidity of cure depended very greatly on climate (i.e., insolation), and he was unable to get the phenomenal results obtained by Dr. Rollier, which enabled more conservative methods to be adopted. While the treatment of surgical tuberculosis must be essentially conservative in hospitals where one has not the most 
favourable climatic conditions, operative treatment combined with general treatment will give the most speedy, though perhaps slightly less perfect, results. Some results of specific treatment of cold abscesses and sinuses were given. It was difficult to prevent sinus formation, especially during the winter months. Cold abscesses were treated by repeated aspiration with a measure of success. Some who did not respond to this were treated by open operation, with careful surgical technique, and the wound sutured. This was successful in onethird of the cases. The use of modifying fluids has given the best results in cold abscesses. Calot's Fluid No. I gives the best results, though sometimes naphthol-camphor was used successfully. The treatment of sinuses is a difficult problem, a large proportion of cases having these on admission. For afebrile cases Calot's paste was useful, with striking results in some cases. Dr. Taylor referred to the good results of deep X-ray therapy in massive cervical glands, as carried out by Dr. Henderson, Radiologist to the Hospital. Reference was made to the necessity for extreme care in applying antisyphilitic treatment to patients with a positive Wassermann reaction and a definite tuberculous lesion, as the latter is apt to become activated after an anti-syphilitic injection.

A special feature of the Section was the largely attended lecture and cinematograph demonstration given by Dr. Rollier of Leysin, on the "Rôle of the Sun in the Treatment of Tuberculosis," in which the lecturer gave a very full demonstration of his well-known methods. The lecture was profusely illustrated by lantern slides and cinematograph films.

Another interesting feature of the Section was the exhibit of X-ray films by Dr. Henderson, Radiologist to the Public Health Department, Glasgow, which comprised about Ioo films of different lesions of the chest, with special reference to those liable to be mistaken for pulmon. ary tuberculosis and those presenting difficulties in interpretation. As an aid to their study a brief clinical description was given of each case. 